Trascender, Contabilidad y Gestión. Vol. 5, Núm. 14 (mayo - agosto del 2020). Universidad de Sonora. Departamento de Contabilidad. ISSN: 2448-6388. Reserva de Derechos 04-2015-04172070800-203.

\title{
La salud laboral en carpinterías, un caso de estudio con enfoque contable socio ambiental
}

\author{
Occupational health in carpentry, a case study \\ with socio-environmental accounting approach
}

José María Gastélum Cano ${ }^{1}$

Recibido: 14 de enero de 2020 .

Aceptado: 14 de febrero de 2020.

DOI: https://doi.org/10.36791/tcg.v0i14.82

JEL: J28. Salud industrial. Q56. Contabilidad medioambiental.

\section{Resumen}

En este trabajo, se busca abordar los temas de la contabilidad, las teorías contables y de gestión con respecto al medioambiente, la salud, y los riesgos de trabajo relacionados a las carpinterías y derivados de la calidad del medio ambiente laboral, y de la relación crítica entre estos ámbitos que a simple vista luce inverosímil.

Se comenta la contabilidad como una herramienta de percepción y análisis, su relación con la gestión y su papel como evaluadora de acciones. Además, se expone la factibilidad de usar la misma con el objetivo de evaluar las repercusiones hacia el medio ambiente y así tomar decisiones más responsables social y ecológicamente. También se habla de la posibilidad que deja abierta la teoría normada en nuestro país, de utilizar la contabilidad con estos fines. Después, situándonos en el tema de este trabajo, se habla de la relación entre los costos ambientales y la calidad del medioambiente interno laboral, para situarnos en lo relacionado al caso de estudio: las carpinterías. Finalmente, se exhiben las posibles exposiciones riesgosas y efectos a la salud derivados de laborar en estos lugares de trabajo, sin las precauciones debidas.

Palabras clave: salud, carpinterías, costos, medioambientales.

\begin{abstract}
This paper seeks to address the issues of accounting, accounting and management theories regarding the environment, health, and work risks
\end{abstract}

\footnotetext{
1 José María Gastélum Cano. Licenciado en Contaduría Pública, Licenciado Químico Biólogo Clínico. Especialidad en Ciencias del Laboratorio Clínico, Maestría en Ciencias (grado en proceso). Adscrito al Centro de Investigación en Alimentación y Desarrollo A.C., ejerciendo en el Laboratorio de Genética y Biología Molecular de Plantas. Correo: jose.gastelum.mc19@alumnos.ciad.mx
} 
related to carpentry and derived from the quality of the working environment, and the critical relationship between these areas that at first glance looks implausible.

Accounting is commented as a tool of perception and analysis, its relationship with management and its role as an evaluator of actions. In addition, the feasibility of using it is exposed in order to assess the impact on the environment and thus make more socially and ecologically responsible decisions. There is also talk of the possibility that leaves open the normative theory in our country, of using accounting for these purposes. Then, on the subject of this work, we talk about the relationship between environmental costs and the quality of the internal working environment, to be related to the case study: carpentry. Finally, the possible risky exposures and health effects arising from working in these workplaces are exhibited, without proper precautions.

Keywords: health, carpentry, costs, environmental.

\section{Introducción}

La actividad productiva puede clasificarse de diferentes maneras y bajo diferentes enfoques. Uno de estos enfoques es referente a la cantidad de individuos que involucra, es decir, si se hace en individual o en colectividad. Así podemos encaminarlo en este trabajo, a aquellas personas que en conjunto ejecutan una actividad o conjunto de actividades y obtienen beneficios a través de ella satisfaciendo la demanda de artículos o servicios, propio a la coyuntura actual mundial, estas colectividades pueden representar para fines tributarios, una persona física o una persona moral.

Según Romero-López (2010:107), El concepto de entidad económica abarca tanto a personas físicas como morales que se dediquen a cualquier actividad empresarial, independientemente del tipo de ésta, ya sea con o sin propósitos de lucro. Se hace ésta última aclaración, pensando en aquellas organizaciones que persiguen un bien social y que únicamente reciben ingresos suficientes para solventar sus egresos derivados de sus operaciones actuales y futuras, que de alguna manera, tendrán consecuencias sobre el medioambiente y la sociedad. Sin embargo, son las entidades económicas con propósitos lucrativos en particular las industriales, las que tienen un efecto mayor sobre dichas esferas, de hecho, es la actividad industrial la que provoca una cadena de deterioro, existen cantidad de ejemplos de daño a la calidad del agua, aire y suelo, que a su vez afectan el clima y otros servicios ecológicos que se pierden o deterioran (Medellín, 2007 citado por De la Rosa, 2009:21).

Como plantea Romero-López (2010:107) se puede referir a entidad económica como

"aquella unidad identificable que realiza actividades económicas, y que está constituida por un conjunto integrado de recursos humanos, materiales y financieros (actividades económicas $y$ recursos) administrados por un centro de control independiente que toma decisiones encaminadas al cumplimiento de los fines específicos para los que fue creada."

Por otra parte, las entidades económicas pueden diferenciarse en las que son con fines de lucro, cuyo principal propósito es resarcir y retribuir a los inversionistas su inversión a través de rendimientos o reembolsos, y aquellas sin propósitos de lucro en las que sus patrocinadores no reciben retribución económica alguna derivada de sus aportaciones, y por tanto no resarce económicamente la inversión... (Romero-López, 2010:107). 
En cambio, la empresa se define como

“la combinación de recursos humanos, técnicos, materiales, naturales, financieros y capital, cuyo objetivo natural y principal es la prestación de servicios a la comunidad, o la obtención de ganancias, coordinada por una autoridad encargada de tomar decisiones acertadas para el logro de los objetivos preestablecidos (RomeroLópez, 2010:107).

Dado a que las definiciones son muy similares, para propósitos del presente trabajo, se referirá indistintamente entre el término entidad económica y empresa, ya que ésta, entra de hecho también dentro del concepto de "organización”.

Es importante notar como en los dos casos la toma de decisiones se vuelve un factor determinante del sentido de una entidad económica, ya que mediante el correcto desempeño de éste proceso, se logrará una adecuada aplicación de recursos, de manera que logrará sobrevivir y alcanzar exitosamente el objetivo para el cual fue creada. De hecho, la característica básica que define la realización de una actividad es la exigencia de un proceso de toma de decisiones, tal como lo enuncia Blanco-Dopico (2000:1-5, citado por Romero-López, 2010:9). En definitiva, todas las actividades económicas suponen un proceso de decisión en un contexto de incertidumbre.

Debido a que las decisiones conllevan riesgos empresariales.... hacen que la información contable se convierta en un importante instrumento que informa sobre elementos o medios económicos de la empresa y sobre los acontecimientos relacionados con el desarrollo de su actividad (Romero-López, 2010:10). Por tanto, la información financiera debe ser un reflejo real, fiel, y nítido de las operaciones, transformaciones internas o eventos que afectan económicamente a la entidad emisora de aquella y que por tanto exhiban el patrimonio, los derechos y las obligaciones de ésta tal y como son (De la Rosa 2009:31, Romero-López, 2010:108). Dicha información es el producto del proceso contable, que abarca el reconocimiento inicial, registro de las transacciones u operaciones, transformaciones y eventos llevados a cabo por las empresas; su valuación, reconocimiento posterior, presentación y revelación de la misma (Romero-López, 2010:10), ésta es la finalidad de la contabilidad financiera (Romero-López, 2010:79).

Por lo anterior, la directiva demandará toda la información que haya a la disposición para garantizar la buena marcha de la entidad, ésta necesidad de información, será sólo satisfecha a través de la percepción, identificación, desglose, clasificación, análisis, presentación e interpretación de todos los factores y acontecimientos que rodean y afectan a la empresa, tarea para la cual un sistema contable es requerido.... Sin embargo si queremos brindar información como satisfactor que sea útil a ciertas necesidades, primero debemos conocerlas (RomeroLópez, 2010:74).

Cabe destacar que las necesidades de las empresas cambian a través del tiempo por la coyuntura de la evolución socioeconómica, los cambios ambientales y los avances tecnológicos. Por lo que, inevitablemente la contabilidad debe entrar en el proceso epistemológico que expone Requena (1981: 23-24 citado por De la Rosa, 2009:50) en donde se identifica que se ha formado a través de un lento proceso histórico de elaboración, naciendo de la práctica, evolucionando en la medida en que se ha hecho inevitable e iniciándose en la investigación de los principios, causas y generalizaciones como una necesidad, tal como afirma De la Rosa (2009:51) lo mismo sucede con el estado del arte de la contabilidad medioambiental y sus costos, es decir, coevoluciona a la par de la coyuntura global. 
Así, se sitúa el destino de las organizaciones bajo una curva multifactorial, es decir, que dependerá de las variables que sobre ella son relevantes (las cuales no son pocas, ni constantes, ni estáticas) y aquellas inherentes a las características de cada empresa, por tanto, la contabilidad debe adaptarse a cada empresa ya que por más parecidas que sean entre ellas, como cada persona, cada ente económico es diferente, aunque se dediquen a lo mismo, y por tanto, tienen necesidades -en este caso de información- diferentes para poder ser de utilidad tal como indica la NIF A-4 (IMCP,2019:74; RomeroLópez, 2010:74). Incluso la interpretación puede variar en función de los factores, ya que la posibilidad de que los sistemas contables capten la misma esencia de los conceptos y sean iguales sólo puede ser posible en la medida que las organizaciones lo sean entre sí (Mueller, Gernon y Meek, 1999:2 - 5, citados por De la Rosa, 2009:32).

Como se ha comentado, la información financiera es el producto del proceso contable y la finalidad de la contabilidad financiera para la utilización de la misma por la directiva. Ésta va integrada en los estados financieros, los cuales son el instrumento mediante el cual se comunica la información financiera que precisa el usuario general para fundamentar y tomar decisiones (Romero-López, 2010:79).

Una presentación adecuada de las entidades lucrativas se compone de los siguientes estados financieros: 1 . Balance general o estado de situación financiera, Notas; 2. Estado de resultados, Notas; 3. Estado de flujos de efectivo, Notas; 4. Estado de variaciones en el capital contable, Notas (IMCP, 2019).

Aunque para fines del presente trabajo, se considerarán los primeros dos, ya que de entre toda la información que según la NIF A-3 (IMCP,2019), los estados financieros comunican, la de mayor relevancia para éste texto será la relacionada a su actividad financiera, operativa y las revelaciones sobre su entorno. Esto debido a que sólo analizando, reflexionando y demostrando como las consecuencias derivadas de la forma de operar de una organización afectan en su patrimonio, será la forma en cómo se logrará disuadir a las empresas de que la responsabilidad social corporativa traducida como buenas prácticas en la actividad diaria es un factor determinante para la competitividad de éstas (Silva y Correa, 2010; Keller Dos Santos, 2005) evadiendo entrar al debate citado por De la Cuesta, Valor y Kreisler (2003: 10-11 citados por De la Rosa, 2010:264) de que la Responsabilidad Social Corporativa es un código de conducta de comportamiento empresarial en el que se enfrenta la obligatoriedad contra la voluntariedad.

En los estados financieros, se puede hablar de una estructura en común pero con contenidos diferentes, como generalidad:

"Las partes que integran un estado financiero son tres: Encabezado, Cuerpo y Pie. Así pues, el encabezado, debe estar integrado por: Nombre (razón o denominación social de la entidad), Nombre del estado de que se trate y Fecha o periodo contable por el cual se formulan... El cuerpo, debe presentar todos los conceptos y las cuentas que reflejan el resultado de las operaciones de la entidad, su situación financiera y sus cambios, así como las variaciones experimentadas en el capital contable... su contenido debe ser significativo, relevante, veraz y comparable.... Todas las cuentas y elementos que lo integren deben estar valuados $y$ presentados conforme a las normas (emitidas en México por el IMCP)... Mientras que el pie incluye las firmas de las personas que lo elaboraron, revisaron, autorizaron, etc. Finalmente, las notas y demás material explicativo pueden presentarse en el cuerpo del estado, al pie o en hoja por separado, pero 
siempre debe relacionarse la nota con el renglón del estado a que corresponde” (Romero-López, 2010:207 - 209).

En cuanto a Los recursos y sus fuentes:

"a una fecha determinada se registran ... en el balance general o estado de situación financiera, que permite conocer los recursos económicos que utilizó la entidad para alcanzar sus objetivos, clasificados en orden a su disponibilidad, y las fuentes de donde provienen, ya sean externas: que son obligaciones con los acreedores $y$ proveedores de bienes y servicios, clasificadas por su exigibilidad, o internas: que son la aportación de socios, dueños o propietarios de la empresa, todos ellos a una fecha” (RomeroLópez, 2010:205).

\section{Mientras que:}

"El resultado de sus operaciones en un periodo dado, el cual se presenta... en el estado de resultados, mediante el que se pueden juzgar los resultados de operación generados por la actividad de la empresa, pues permite analizar el desarrollo de la empresa en un periodo, medido normalmente por la utilidad o pérdida neta resultante” (Romero-López, 2010:205).

En gran medida el resultado de las operaciones está afectado por los costos cuya existencia y efecto aparecen reflejados en el estado de resultados, éstos son un componente esencial de la actividad productiva, el cual representa una erogación recuperable como requerimiento ubicuo de la actividad productiva, incluso el más simple de los trabajos requiere de la inversión del recurso tiempo. De esta forma, asintiendo con lo dicho por Del Río-González (2003: I-9) el costo de inversión representa los factores técnicos medibles en dinero, que intervienen en la producción.
Como es clásico, hay que diferenciar entre costos y gastos:

"El costo corresponde a una disminución acumulada de los beneficios económicos futuros fundadamente esperados por una entidad durante el periodo contable, y provoca un efecto desfavorable sobre su utilidad neta; también representa una disminución de activos o un incremento de pasivos y, en consecuencia, una disminución del capital o patrimonio contable. Por su parte el gasto es un egreso que no se identifica de manera directa con un ingreso, aunque coadyuva a la generación de éste." (Romero-López, 2010:239).

Por otra parte, en la teoría económica el costo significa el desplazamiento de alternativas, o sea que el costo de una cosa, es el de aquella otra que fue elegida en su lugar (Del Río-González, C., 2003: I-9 -I-10), es así como se concibe el concepto de costo de desplazamiento, que una vez decidida la alternativa, se convierte en Costo de Inversión (Del Río-González, C., 2003: I-9 -I-10). No obstante, aunque el costo de desplazamiento no se refleja como tal en los estados financieros, es muy importante tenerlo en consideración, porqué de éste concepto podemos establecer una comparación entre el hacer, no hacer o dejar de hacer alguna actividad, evaluando así las decisiones tomadas por la gerencia de un ente económico ya sea antes o después de ejecutadas.

Dichos costos de desplazamiento y de inversión, pueden lograr ser captados y medidos en otros conceptos que reflejen las consecuencias en términos de dinero, por medio de una comparación, ya que la repercusión de dicha acción llevada a cabo, no llevada a cabo o dejada de llevar a cabo, puede estar perjudicando más a la empresa de lo que se piensa. Éste indicador, podría ser enfocado a percibir el estado del medio ambiente 
externo o interno, desgraciadamente un indicador de éste tipo daría información después de haberse sufrido consecuencias, sin embargo, ofrece la posibilidad de percatarse posteriormente cuando algo marcha mal y permitiría informar la necesidad de resarcir el daño, reduciendo las consecuencias también para la empresa. En ese caso también, tal como expone De la Rosa, (2009:25):

"la gestión sobre las finanzas, se apega a una red de comunicación de los efectos, en donde el medio de control responde a las características, necesidades de las estrategias y forma de operación de las organizaciones. En cuya línea de funcionamiento la información de lo que pasa, es un detector que se apoya en un indicador o norma preestablecida que utiliza el medio de control para transformar el efecto en la organización en una retroalimentación que modifica el comportamiento hacia lo requerido."

De ésta forma se estaría dando a luz, a un indicador de eficiencia medioambiental en términos monetarios, relacionado a las consecuencias de las acciones de la organización, similar a como lo plantea Picazo (1994 citado por De la Rosa, 2009:64) que informa acerca del desempeño medioambiental de la empresa, actuando en el sistema de calidad como detector de malas decisiones a través de las consecuencias medioambientales registradas (Epson y Birchard, 2000 citados por De la Rosa, 2009:60) traducidas como costos, los cuales está por demás decir, afectan negativamente la utilidad, pero además son evitables en la misma medida que las consecuencias al medioambiente. De hecho:

"los costos medioambientales actuaron en su origen como uno de los catalizadores de la contabilidad medioambiental, ya que se constituyeron en el primer argumento de interés en el conocimiento del daño ambiental como un costo social de las organizaciones, e inclusive fueron señalados como el concepto eje para en razón de ellos, desarrollar la contabilidad medioambiental" (De la Rosa,2009:63).

Sin duda, las actividades organizacionales tienen alguna repercusión en el ambiente contiguo a veces imperceptible inmediatamente. A veces se espera a que los ciclos biogeoquímicos hagan su trabajo natural y eliminen todo rastro de consecuencias de las actividades, pero no siempre es así de sencillo. Frecuentemente se olvida la dependencia perpetua que los seres humanos tienen con los recursos naturales y con el medio ambiente, lo que les afecta a corto o a largo plazo, directa o indirectamente, que también afecta a la sociedad y a las mismas organizaciones de diferentes maneras, dependiendo de su actividad.

\section{Antecedentes}

Teniendo en cuenta la estrecha relación que existe entre los recursos naturales, las organizaciones y el ser humano, surge la necesidad de crear regulaciones ambientales que protejan y propendan por el uso adecuado de estos recursos, pues a partir de ellos se satisfacen las necesidades vitales de la población mundial. (Silva y Correa, 2010:27). Sin embargo, considerando las deficiencias de las leyes nacionales y el aparato legislativo en estas cuestiones (que las tienen, si no, no nos situaríamos en la problemática ambiental actual) que conllevan a una conservación parcial del medio ambiente, además del amplio desconocimiento de las normas ISO 14000 y sumado a esto el escepticismo de los costos medioambientales contables en el ámbito nacional (Morales, 1998 citado por De la Rosa, 2009:46); una propuesta nada descabellada sería disuadir a las organizaciones, que los perjuicios medioambientales afectan también a éstas en el curso y resultado de su actividad económica.

No obstante, antes de lograr el objetivo expuesto, primero hay que corregir los detalles que limitan a la contabilidad de costos medioambiental. Lo cual es 
posible gradualmente en un proceso de coevolución de la contabilidad con la demanda de nueva información a través del tiempo. Un proceso, en apariencia análogo a la evolución de las especies a las condiciones del planeta al paso de las eras, el cual puede culminar en un paulatino replanteamiento de la teoría contable algo parecido a lo que sugiere la corriente ontológica de estructuración de la contabilidad medioambiental (Cámara, 1996; Wainstein et al., 1996, Schaltegger, Müller y Hindrichsen, 1996, Bennett et al., 2002; Birkin y Woodward, 1997a; Stone, 1997; Schimidheiny et al., 1998; Carrasco, Correa y Larrinaga, 1999; Birkin, 2000; Bennet, 2002 citados por De la Rosa, 2009:59).

Lo anterior sólo puede ser logrado, a través de pequeños pasos que tiendan al cambio de los paradigmas de la contabilidad actual, haciendo presión en base a necesidades de información generadas a través de la integración de la contabilidad medioambiental vía la corriente tradicionalista. Ésta, sostiene que los asuntos medioambientales deben ser atendidos por la contabilidad a través de la normativa contable que ha regulado desde los años setenta los procedimientos de registro y presentación de la información contable de las organizaciones (Thompson, 2002; Asociación Española de Contabilidad y Administración de Empresas, 1999; White, 1999, citados por De la Rosa, 2009:55). Trayendo consigo la ventaja, que al integrar la contabilidad medioambiental a la contabilidad regulada obtiene los beneficios de observación y ayudará colateralmente a estandarizar y normalizar el trabajo de los contadores en éste aspecto (De la Rosa, 2009:56).

El modelo económico vigente y el desarrollo industrial, han provocado que los centros de trabajo de la rama de la transformación, sean foco frecuente de malestares ocupacionales. Esto como consecuencia de que estos lugares se suelen trabajar con materias primas y materiales nocivos en diferente grado según el giro.
Sumado a esto, algunos procesos de fabricación involucran la liberación de contaminantes como inherentes consecuencias de la producción, los cuales reducen la calidad del medio ambiente. Estas consecuencias, son evitables hasta cierto punto, gracias a los avances tecnológicos de los últimos años, los esfuerzos de instituciones de investigación, agencias gubernamentales y organizaciones ambientales, aunque continúan sucediendo frecuentemente en países en desarrollo como México. Una de las causas señaladas de dicha persistencia, es la falta de motivación de las empresas por evitar dichas situaciones. Por otra parte, la investigación de las relaciones entre la amplia gama de agentes utilizados en la industria y sus repercusiones a la salud, son aún una rama de investigación en estudio.

\section{Marco Teórico}

La contabilidad, tal como señala Miller (1994, citado por Lovell y MacKenzie, 2011:708) puede ser vista como una tecnología al permitirnos intervenir, dar visibilidad de los eventos, procesos y de la gente que se dirige en una empresa (corporate governance). Algo similar a un órgano de una organización con capacidad analítica, que como indica Birkin (1997-2000, citado por De la Rosa, 2009) puede funcionar como un mecanismo de control de la gestión de la organización. Dicho órgano, puede ayudar a mejorar la situación del medio ambiente tanto interno (dentro del área de trabajo), como externo, trayendo a la vez beneficios a la organización (Aranguren y Ochoa, 2008; Cortés-Landázury, 2011; Déniz-Mayor,2006; De la Rosa, 2009;Label, 2000;Lovell y MacKenzie, 2011; Silva y Correa, 2010; Wilcox, Cameron y Xifra, 2006), aunque a corto plazo aparente sólo una reducción de los beneficios en el resultado lo cual puede ser obviamente, objeto de rechazo inmediato y de controversia (DénizMayor, 2006; Lovell, H. y MacKenzie, D.; 2011). Éste hecho da la impresión, de que las acciones de protección ambiental y el objetivo económico desarrollista de las organizaciones no tienen punto de conciliación, ya que la tendencia de los procesos productivos se orienta hacia la 
eficiencia y la reducción de costos, para generar mayores utilidades a corto plazo (Cariño, 2000, citado por De la Rosa, 2009:17).

La teoría de gestión, establece que la organización genera un proceso dinámico de interacción con su entorno en un tiempo y contexto específico, para cumplir con sus objetivos y actividades necesarias (De la Rosa, 2009:25). Por tanto, en el gobierno corporativo, la perspectiva contable de gobernabilidad significa utilizar mecanismos y metodologías con una relación muy cercana a las finanzas (Brennan y Solomon, 2008 citados por De la Rosa, 2009). De tal forma, que la teoría doctrinal contable se une a las finanzas incorporando conceptos de control y definición de los orígenes y aplicaciones financieras (De la Rosa, 2009:29).

El sistema de información contable es un componente central de casi todos los sistemas de información gerencial (MIS, por sus siglas en inglés). Al mismo tiempo, el sistema de administración ambiental necesita estar totalmente integrado con otros sistemas de información y con las metas y objetivos de la empresa (Label, 2000:63). Así, la contabilidad se establece como un mecanismo de evaluación de desempeño, o como evidencia de las prácticas de autoridad y el valor de los gerentes (De la Rosa, 2009:29-30), y por consecuencia, de las acciones de las empresas con respecto a la sociedad y al medioambiente como práctica de la responsabilidad social. Ésta, ha venido a ser un indicador importante en los últimos años, relacionándose con la competitividad corporativa (Silva y Correa, 2010:30), la credibilidad, la confianza del público (Wilcox, Cameron y Xifra, 2006) y la legitimidad (Aranguren y Ochoa, 2008:134) del ente económico de acuerdo a la expectativa social. Inclusive puede ser de importancia futura para terceros interesados en la regulación de este tema, como son gobiernos, mercados financieros, inversionistas y otros organismos (ACCA , 2009 citado por Lovell y MacKenzie, 2011:721, Ortas y Moneva,
2011 citados por Correa y Moneva, 2001:201).

Otra ventaja importante al cumplir con las leyes ambientales, es el logro de grandes ahorros en dinero al evitar el pago por concepto de multas anticontaminantes. Asociados están los costos ahorrados en la prevención de la contaminación, tales como la limpieza y restructuración del medio ambiente (Label, 2000:60). Por tanto, es posible situar la contabilidad como una opción viable en cuanto a su utilización para registrar y presentar información medioambiental (Déniz-Mayor, 2006; Lovell y MacKenzie, 2011; De la Rosa, 2009). Ya que la función de la contaduría y de las actividades de la auditoría relacionadas, ofrecen un gran número de áreas donde los sistemas de administración contable y financiera se interconectan con los sistemas de administración ambiental (Label, 2000:63). De hecho, son los contadores los expertos (en el cálculo, medición, etc.) y conocedores de la importancia para la generación de políticas ambientales. Esto se debe a que -como ocurre en el caso de la contabilidad del carbono en Europa-, han contribuido a un mejor panorama en la cuestión del cambio climático, remodelación, extensión del mercado y procedimientos de reporte corporativo ya existentes (Lovell y MacKenzie, 2011:712).

No obstante, existen argumentos en contra como el de Stephan (1992, citado por Déniz-Mayor, 2006:159), quien alega que los estados financieros actuales no se han desarrollado para incluir "hechos" externos a la propia entidad contable. Además, agrega que el tiempo requerido para rediseñar estos modelos financieros y contables, podrían originar retrasos prolongados, al igual que la necesidad de incluir información científica y estadística, difícil de integrar en las estructuras de los actuales sistemas contables. En contraste hay autores quienes aseguran que la contabilidad puede ser utilizada para registrar variables socio ambientales sin modificar las prácticas y modelos ya establecidos (De la Rosa, 2009; Déniz-Mayor, 2006, Lovell, y MacKenzie, 2011). Lo anterior se vuelve factible desde el punto de vista de 
Botosan (1997, citado por Aranguren y Ochoa, 2008:127) quien asegura que la información numérica tiene mayor contenido informativo. Dicha idea es apoyada en el terreno de la información social (Ernst y Ernst, 1978, citado por Aranguren y Ochoa, 2008:127) bajo el argumento de que la información divulgada mejora cuando se ofrece información de tipo cuantitativo. Esto se debe a que la empresa está especificando la cantidad de esfuerzo que está dedicando a esa área concreta de responsabilidad social, expresado de forma monetaria o no monetaria. O bien, información respecto la cantidad de esfuerzo que no se está dedicando, posibilitando la medición del costo que le está generando evitar adoptar ciertas políticas para el abatimiento de prácticas dañinas para el medio ambiente.

Esta tendencia de contabilidad ambiental es perfectamente permitida incluso por la teoría normada en México, cuyo organismo regulador es el IMCP (Instituto Mexicano de Contadores Públicos). Ya sea por la libertad de las organizaciones de utilizar su propio plan de cuentas, de acuerdo a su plan de gestión, influencia de variables endógenas, política tributaria o naturaleza de su capital (De la Rosa, 2009:34), o bien sea por la interpretación que se le da a cada concepto de acuerdo a la naturaleza de la organización. Lo anterior, nos sitúa en un marco contextual que contempla la emergencia de una contabilidad medioambiental que intenta satisfacer la demanda creciente de rendición de cuentas (a internos y stakeholders), desde una contabilidad financiera, obligada a evolucionar para adaptarse a las necesidades variantes del usuario. En este caso, originadas por la demanda en ascenso de terceros interesados, seguramente convencidos de que tal como denuncia Hardin (1968:1243) sólo aumentaremos la miseria humana si en el futuro inmediato, no asumimos que el mundo disponible para la población es finito.
La principal justificación para la contabilidad medioambiental es obtener y revelar el conocimiento del efecto gradual o acumulado del impacto de la empresa en el medioambiente $\mathrm{y}$ ayudar a acceder a un comportamiento correcto con el medio ambiente (De la Rosa, 2009:50). Sin embargo, por nacer al amparo de la contabilidad corriente, presenta limitaciones surgidas por la imposición de las reglas tradicionales de esta contabilidad, limitaciones tales como:

"el registro de los costos de inversiones ambientales en los costos de producción; la falta de reconocimiento de los beneficios tangibles de su registro, optando por no incluirlos; la ausencia de compromiso con las nociones ambientales de los límites de la actividad económica y por tanto la ausencia de información al respecto; una visión a largo plazo de los asuntos medio ambientales de la empresa, por su falta de certidumbre; el uso de la teoría de la firma o de la agencia, para identificar la propiedad de los recursos, por lo que la propiedad del aire y del agua es parte del capital natural y no propiedad privada." (De la Rosa, 2009:54-55).

Lo antes dicho, destaca lo escrito por Hardin (1968:1245), cuando expone:

"El hombre razonable encuentra que su parte de los costos de los desperdicios que descarga en los recursos comunes es mucho menor que el costo de purificar sus desperdicios antes de deshacerse de ellos. Ya que esto es cierto para todos, estamos atrapados en un sistema de "ensuciar nuestro propio nido", y así seguirá mientras actuemos únicamente como libres empresarios, independientes y racionales." 
Cabe coincidir en éste trabajo con la propuesta de Picazo (1994 citado por De la Rosa, 2009:56) quien propone una selección estratégica de datos para integrar un sistema inteligente de información e identificar a los costos contables medioambientales como costos internos del proceso productivo de una gerencia "verde". La definición de esta, debe darse contablemente y evaluarse con indicadores internos. Esto puede inducirse por la puesta en marcha de nuevas prácticas que se arraiguen con el tiempo hasta llegar a un punto en el que los contadores se encuentren dispuestos a recibir guías emitidas por los organismos reguladores con el deseo de hacer las prácticas contables más sencillas. Esto permitirá la posibilidad de comparación con los competidores, tal como sugieren las entrevistas citadas por Lovell y MacKenzie (2011:726-727), en el caso de la contabilidad de carbono y los derechos de emisión.

Otro enfoque, es el de los costos ISO, definidos como aquellos que surgen para conocer el efecto monetario de las tecnologías ambientales en las organizaciones [...] y que son la interpretación de los costos verdes de las normas ISO 14000 (De la Rosa, 2009:67). Lo cual parece una solución contundente y viable desde el punto de vista de Label (2000). Las ISO 14000 son una serie de normas para Sistemas de Administración Ambiental (EMS por sus siglas en inglés) que incluye la auditoría ambiental (Label, 2000:56-57). Estas normas, incluyen las preocupaciones de los interesados, expectativas de los consumidores y acreedores, las relaciones con la comunidad e inversionistas, así como el potencial para mejorar el control de costos y la reducción del importe de las primas de seguros. Además, proporcionan razones firmes para que las empresas adopten la ISO 14000 y satisfagan los requerimientos de la certificación (Label, 2000:64). Otros beneficios mencionados por Label (2000) incluyen: disminución regulatoria, incremento en la eficiencia, reducción del riesgo en la limpieza total del medio ambiente y un trato gubernamental preferente. Un beneficio final es que la ISO 14000 dificultará que los países utilicen los asuntos ambientales como una barrera al comercio.

Los costos ISO 14000 parecen una propuesta un tanto incompleta y lejana de ser la solución para la totalidad de las organizaciones en el mundo entero, ya que como Label (2000:59) comenta, la ISO 14000 no especifica qué tanta contaminación puede producir una empresa o cuánta debería eliminarse. Más bien, las series ISO 14000 integran una lista completa de precisas prácticas de administración, una plantilla para cualquier empresa que desee establecer su propio sistema para ocuparse de los asuntos ambientales. $\mathrm{Y}$ aunque los beneficios argumentados parecen tentadores, Howard (1996 citado por Label, 2000:61) comenta que la auditoría necesaria para la ISO 14000 se hace con una base de instalación por instalación, cuyo costo pudiera estar por encima de los \$15000 dólares, lo cual es una cantidad exorbitante de dinero que muchas organizaciones, principalmente en los países en vías de desarrollo, seguramente no están en posición de sacrificar por el medio ambiente. Además, dichas normas son ampliamente desconocidas.

Por otro lado, el tratamiento de dichos costos medioambientales puede darse dentro de una fusión de la teoría de costos de transacción y el criterio de costos sociales con algunas modificaciones. La primera, integra los costos tradicionales al medio ambiente y une a los costos comunes los medioambientales usando los principios de contabilidad (De la Rosa, 2009:64). La segunda, parte de tomar en cuenta el límite de vida de los recursos naturales, el valor de consumo de los recursos y el deterioro ambiental acumulado percibido por la comunidad, incluyendo la salud de los empleados. Esto puede entrar dentro de los principios de contabilidad, si tomamos en cuenta que éstos, señalan que el registro de los costos (en este caso los medioambientales) es paralelo a su ingreso, independientemente de su fecha de cobro (De la Rosa, 2009:64). Y efectivamente, los costos medioambientales 
lo son, por su relación causal dependiente del proceso de producción que genera los ingresos (Medellín, 2007 citado por De la Rosa, 2009:21; Miranda, 2001 citado por Silva y Correa, 2010:27; Azqueta y De la Cámara, 2008:61-62; Keller, 2005:78; Manahan, 2010:7; Pontelli, Ingaramo, Zanazzi, Chayle, Rodríguez y Beale, 2010:8).

Los costos de transacción, son los costos de usar el mercado. De acuerdo con Dahlman (1979 citado por Vargas, 2005), son los costos de búsqueda de información, negociación, decisión, formulación y aplicación de las políticas. Una transacción es la transferencia de bienes y servicios a lo largo de una frontera organizacional, es un concepto que incluye tanto la noción de intercambio como la de contrato (Salgado, 2003:63-64). En los costos de transacción, las categorías de medición de los costos ambientales (Rast y Jacqueline, 2001 citados por De la Rosa, 2009:64) parten de dos criterios básicos: el primero es la consideración de costos directos, como la mano de obra, la energía utilizada, las acciones remediales, los servicios profesionales, etc. y el segundo los costos, relacionados. En aquellos, se puede dibujar directriz marcada, con las dimensiones contables de los costos sociales, los cuales toman como criterio la internalización de las externalidades, producto del impacto al medio ambiente (De la Rosa, 2009:64) y a su vez, del proceso de producción. Una de citadas internalizaciones que se pueden relacionar con los costos directos, sería la apropiación y reconocimiento del daño ambiental, por ejemplo, el deterioro de la salud de los empleados.

"éstos costos se ven afectados por diversas situaciones como las condiciones generales, los contratos y subcontratos, el riesgo, el reemplazo de equipos, los sistemas de manejo de desechos, la duración de las especificaciones $y$ consideraciones por remediación completa, tiempo de atención, rango de contaminación, naturaleza, volumen de la contaminación, y los niveles tecnológicos necesarios” (De la Rosa, 2009:64).

Sin duda, el deterioro de la salud de los empleados se relaciona con todos estos factores, tal como lo muestra la NOM-010-STPS-1999, "Condiciones de seguridad e higiene en los centros de trabajo donde se manejen, transporten, procesen o almacenen sustancias químicas capaces de generar contaminación en el medio ambiente laboral”, en el punto 9, llamado "Control” dice:

"9.2 Cuando la exposición del trabajador a las concentraciones de las sustancias químicas contaminantes rebase los LMPE del Apéndice I [...] aplicar un programa de control, en el que se implementarán las siguientes medidas, considerando la naturaleza de los procesos productivos, aspectos tecnológicos, económicos, factibilidad y viabilidad:

a) sustitución de las sustancias del medio ambiente laboral, por otras sustancias cuyos efectos sean menos nocivos;

b) modificación o sustitución de los procesos o equipos, por otros que generen menor concentración de contaminantes del medio ambiente laboral;

c) modificación de los procedimientos de trabajo, para minimizar la generación de contaminantes del medio ambiente laboral o la exposición del trabajador;

d) aislamiento de los procesos, equipos o áreas para evitar la dispersión de los contaminantes del medioambiente laboral;

e) aislamiento del trabajador del medio ambiente laboral contaminado, a una atmósfera 
libre de contaminantes;

f) utilización de sistemas de ventilación por extracción localizada, para evitar la dispersión de los contaminantes al medio ambiente laboral;

g) utilización de sistemas de ventilación general.

9.3 Las siguientes medidas de control deben ser aplicadas de inmediato mientras se cumple con lo establecido en el apartado anterior, con el fin de no exponer a los trabajadores a concentraciones superiores a los LMPE establecidos en el Apéndice I:

a) limitación de los tiempos y frecuencias de exposición del trabajador a las sustancias químicas contaminantes;

b) dotar a los trabajadores del equipo de protección personal específico al riesgo. En la selección de este equipo, el patrón debe considerar sus factores de protección y un programa de capacitación y mantenimiento del mismo, a fin de que el trabajador no se exponga a concentraciones que estén por arriba de los $L M P E$, y que el equipo de protección personal se conserve en buenas condiciones de trabajo, de acuerdo a la NOM-017-STPS-2008.” (Secretaría de Trabajo y Previsión Social, 2008:11-12).

La norma anteriormente citada, busca reducir el tiempo de exposición y la concentración del contaminante en el área de trabajo para evitar los daños a la salud de los trabajadores, en lo que las variables técnicas son modificadas. Denotando la relación causal que existe entre los factores antes citados y los costos de transacción. El enfoque de la Norma Oficial Mexicana, es dirigido a la protección del empleado, lo cual debe ser una prioridad para la prevención de accidentes y enfermedades ocupacionales. En todo caso, su repercusión en los costos podría ser estimada en base a datos obtenidos de documentos fuente como la tarjeta de control del personal, tarjetas de asistencia, registro de siniestralidad y coeficientes de rotación de empleados, que proporcionen información sobre el desempeño y asistencia de los empleados. Además, tomando en cuenta los costos derivados de los acontecimientos y asignando los mismos a los esfuerzos aplicados en función del tiempo.

En la tabla 1 se hace un análisis del marco teórico, lo cual representa la espina dorsal de este trabajo.

Tabla 1. Resumen marco teórico

\begin{tabular}{|l|l|}
\hline Propuesta teórica & Argumento \\
\hline $\begin{array}{l}\text { La contabilidad como } \\
\text { tecnología }\end{array}$ & $\begin{array}{l}\text { La contabilidad, puede ser vista como una tecnología al permitirnos } \\
\text { intervenir, dándonos visibilidad de los eventos y procesos, y de la gente } \\
\text { que se dirige en una empresa (corporate governance) (Miller, 1994 citado } \\
\text { por Lovell y MacKenzie, 2011:708). Al mismo tiempo evidencia las } \\
\text { prácticas de la autoridad y el valor de los gerentes De la Rosa, 2009:29- } \\
\text { 30). }\end{array}$
\end{tabular}


Tabla 1. Continuación...

\begin{tabular}{|c|c|}
\hline Propuesta teórica & Argumento \\
\hline $\begin{array}{l}\text { La contabilidad como } \\
\text { tecnología en la gestión del } \\
\text { medio ambiente }\end{array}$ & $\begin{array}{l}\text { Por lo tanto, puede funcionar como un mecanismo de control de la gestión } \\
\text { de la organización, para mejorar la situación del medio ambiente tanto } \\
\text { interno (dentro del área de trabajo), como externo (Birkin, 1997-2000, } \\
\text { citado por De la Rosa, 2009). }\end{array}$ \\
\hline $\begin{array}{l}\text { La contabilidad de asuntos } \\
\text { relacionados al } \\
\text { medioambiente, permitida } \\
\text { por las normatividad del país }\end{array}$ & $\begin{array}{l}\text { Esta tendencia de contabilidad ambiental es perfectamente permitida } \\
\text { incluso por la teoría normada en México, cuyo organismo regulador es el } \\
\text { IMPC, así sea por la libertad de las organizaciones de utilizar su propio } \\
\text { plan de cuentas de acuerdo a su plan de gestión o influencia de variables } \\
\text { endógenas, como la política tributaria o la naturaleza de su capital (De la } \\
\text { Rosa, 2009:34), o bien sea por la interpretación que se le da a cada } \\
\text { concepto de acuerdo a la naturaleza de la organización. }\end{array}$ \\
\hline $\begin{array}{l}\text { La organización en relación } \\
\text { con su } \\
\text { entorno }\end{array}$ & $\begin{array}{l}\text { Por otra parte, la teoría de gestión establece que la organización genera un } \\
\text { proceso dinámico de interacción con su entorno en un tiempo y contexto } \\
\text { específico, para cumplir con sus objetivos y actividades necesarias. (De la } \\
\text { Rosa, 2009:25) }\end{array}$ \\
\hline $\begin{array}{l}\text { Utilidad de la contabilidad en } \\
\text { el gobierno corporativo }\end{array}$ & $\begin{array}{l}\text { En el gobierno corporativo, la perspectiva contable de gobernabilidad } \\
\text { significa utilizar mecanismos y metodologías con una relación muy } \\
\text { cercana a las finanzas (Brennan y Solomon,2008 citados por De la Rosa, } \\
\text { 2009).De tal forma que la teoría doctrinal contable se une a las finanzas, } \\
\text { que incorpora en ella conceptos de control y definición de los orígenes y } \\
\text { aplicaciones financieras... (De la Rosa, 2009:29). }\end{array}$ \\
\hline $\begin{array}{l}\text { Razones para utilizar la } \\
\text { contaduría como herramienta } \\
\text { de cuantificación de costos } \\
\text { socioambientales. }\end{array}$ & $\begin{array}{l}\text { Es así, como la función de la contaduría y de las actividades de la auditoría } \\
\text { interna y externa relacionada ofrece un buen número de áreas donde los } \\
\text { sistemas de administración contable y financiera se interconectan con los } \\
\text { sistemas de administración ambiental (Label, 2000:63). Además, son los } \\
\text { contadores los propios expertos (en el cálculo, medición, etc.) y } \\
\text { conocedores de gran importancia para la generación de políticas. (Lovell, } \\
\text { H. y MacKenzie, D 2011:712). }\end{array}$ \\
\hline
\end{tabular}


Tabla 1. Continuación...

\begin{tabular}{|c|c|}
\hline Propuesta teórica & Argumento \\
\hline $\begin{array}{l}\text { Ventajas de cuantificar y } \\
\text { contabilizar daños } \\
\text { relacionados con la sociedad y } \\
\text { el medio ambiente }\end{array}$ & $\begin{array}{l}\text { Utilizar la contabilidad como herramienta para medir costos } \\
\text { socioambientales se vuelve factible, ya que desde el punto de vista de } \\
\text { Botosan (1997, citado por Aranguren y Ochoa, 2008:127) la información } \\
\text { numérica tiene mayor contenido informativo, idea apoyada en el terreno de } \\
\text { la información social (Ernst y Ernst, 1978, citado por Aranguren y Ochoa, } \\
\text { 2008:127) bajo el argumento de que la información divulgada mejora } \\
\text { cuando se ofrece información de tipo cuantitativo, ya que la empresa está } \\
\text { especificando la cantidad de esfuerzo que está dedicando a esa área } \\
\text { concreta de responsabilidad social, ya sea expresado de forma monetaria o } \\
\text { no monetaria. }\end{array}$ \\
\hline $\begin{array}{l}\text { Las ventajas de ser } \\
\text { responsable social y } \\
\text { ecológicamente. Razones para } \\
\text { ser un buen ciudadano } \\
\text { corporativo e invertir } \\
\text { esfuerzos y recursos en serlo. }\end{array}$ & $\begin{array}{l}\text { La responsabilidad social, que en los últimos años, ha venido a ser un } \\
\text { indicador importante, relacionado con la competitividad corporativa (Silva } \\
\text { y Correa, 2010:30), la credibilidad, la confianza del público (Wilcox, } \\
\text { Cameron y Xifra, 2006) y la legitimidad (Aranguren y Ochoa, 2008:134) } \\
\text { del ente económico de acuerdo a la expectativa social, inclusive puede ser } \\
\text { de importancia futura para terceros interesados en la regulación de este } \\
\text { tema, como son gobiernos, mercados financieros, inversionistas y otros } \\
\text { organismos como indica la ACCA (2009, citado por Lovell y MacKenzie, } \\
\text { 2011:721, Ortas y Moneva, 2011, citados por Correa y Moneva, 2001:201). } \\
\text { Adicional, otra ventaja importante que podría generarse al cumplir con las } \\
\text { leyes ambientales, es el logro de grandes ahorros en dinero al evitar el pago } \\
\text { por concepto de multas anticontaminantes. Asociado con lo anterior, están } \\
\text { los costos ahorrados en la prevención de la contaminación, tales como la } \\
\text { limpieza y restructuración del medio ambiente. (Label, 2000:60). }\end{array}$ \\
\hline $\begin{array}{l}\text { Limitaciones actuales de la } \\
\text { contabilidad } \\
\text { medioambiental }\end{array}$ & $\begin{array}{l}\text { Sin embargo, la contabilidad medioambiental tiene ciertas limitaciones, } \\
\text { como son: el registro de los costos de inversiones ambientales en los costos } \\
\text { de producción; la falta de reconocimiento de los beneficios tangibles de su } \\
\text { registro, optando por no incluirlos; la ausencia de compromiso con las } \\
\text { nociones ambientales de los límites de la actividad económica y por tanto } \\
\text { la ausencia de información al respecto; una visión a largo plazo de los } \\
\text { asuntos medio ambientales de la empresa, por su falta de certidumbre; el } \\
\text { uso de la teoría de la firma o de la agencia, para identificar la propiedad de } \\
\text { los recursos, por lo que la propiedad del aire y del agua es parte del capital } \\
\text { natural y no propiedad privada. (De la Rosa, 2009:54-55). }\end{array}$ \\
\hline
\end{tabular}


Tabla 1. Continuación...

\begin{tabular}{|c|c|}
\hline Propuesta teórica & Argumento \\
\hline $\begin{array}{l}\text { La contabilidad } \\
\text { medioambiental en la } \\
\text { corriente tradicionalista }\end{array}$ & $\begin{array}{l}\text { La corriente tradicionalista, la cual sostiene que los asuntos } \\
\text { medioambientales deben ser atendidos por la contabilidad a través de la } \\
\text { normativa contable que ha regulado desde los años setenta los } \\
\text { procedimientos de registro y presentación de la información contable de las } \\
\text { organizaciones (Thompson, 2002; Asociación Española de Contabilidad y } \\
\text { Administración de Empresas, 1999; White, 1999, citados por De la Rosa, } \\
\text { 2009:55). }\end{array}$ \\
\hline $\begin{array}{l}\text { Ventajas de integrar la } \\
\text { contabilidad medioambiental } \\
\text { a la contabilidad regulada }\end{array}$ & $\begin{array}{l}\text { La ventaja es que al integrar la contabilidad medioambiental a la } \\
\text { contabilidad regulada obtiene los beneficios de observación y ayudará } \\
\text { colateralmente a estandarizar y normalizar el trabajo de los contadores en } \\
\text { éste aspecto (De la Rosa, 2009:56). }\end{array}$ \\
\hline $\begin{array}{l}\text { La propuesta de indicadores } \\
\text { de costos contables } \\
\text { medioambientales vía la } \\
\text { corriente tradicionalista. }\end{array}$ & $\begin{array}{l}\text { Picazo (1994 citado por de la Rosa, 2009:56) propone una selección } \\
\text { estratégica de datos para integrar un sistema inteligente de información e } \\
\text { identificar a los costos contables medioambientales como costos internos } \\
\text { del proceso productivo de una gerencia "verde”, cuya definición debe darla } \\
\text { la normativa contable y valuarse con indicadores internos. }\end{array}$ \\
\hline Los costos ISO & $\begin{array}{l}\text { Los costos ISO, definidos como aquellos que surgen para conocer el efecto } \\
\text { monetario de las tecnologías ambientales en las organizaciones [...] y que } \\
\text { son la interpretación de los costos verdes de las normas ISO } 14000 \text { (De la } \\
\text { Rosa, 2009:67). }\end{array}$ \\
\hline $\begin{array}{l}\text { Beneficios de la observación } \\
\text { de las normas ISO } 14000\end{array}$ & $\begin{array}{l}\text { Las preocupaciones de los interesados, las expectativas de los } \\
\text { consumidores, de los acreedores, las relaciones con la comunidad, con los } \\
\text { inversionistas, así como el potencial para mejorar la capacidad del control } \\
\text { de costos y la reducción del importe de las primas de seguros, } \\
\text { proporcionan razones firmes para que las empresas adopten la ISO } 14000 \text { y } \\
\text { satisfagan los requerimientos de la certificación (Label, 2000:64). Otros } \\
\text { beneficios mencionados por Label (2000)[...] incluyen: disminución } \\
\text { regulatoria, incremento en la eficiencia, reducción del riesgo en la limpieza } \\
\text { total del medio ambiente, y un trato gubernamental preferente. Un } \\
\text { beneficio final es que la ISO } 14000 \text { dificultará que los países usen asuntos } \\
\text { ambientales como una barrera al comercio. }\end{array}$ \\
\hline
\end{tabular}


Tabla 1. Continuación...

\begin{tabular}{|c|c|}
\hline Propuesta teórica & Argumento \\
\hline $\begin{array}{l}\text { Inconvenientes y deficiencias } \\
\text { de las normas ISO } 14000\end{array}$ & $\begin{array}{l}\text { La ISO } 14000 \text { no especifica qué tanta contaminación puede producir una } \\
\text { empresa o cuánta debería eliminarse [...] (Label,2000:59). Además, la } \\
\text { auditoría necesaria para la ISO } 14000 \text { se hace con una base de instalación } \\
\text { por instalación, cuyo costo pudiera estar por encima de los } \$ 15000 \text { dólares. } \\
\text { Por último, dichas normas son ampliamente desconocidas al menos para el } \\
\text { caso de Baja California, como lo demuestra el estudio de Zamorano (1998 } \\
\text { citado por De la Rosa, 2009:46). }\end{array}$ \\
\hline $\begin{array}{l}\text { Teoría de costos de } \\
\text { transacción } \\
\text { (TCT) }\end{array}$ & $\begin{array}{l}\text { La teoría de costos de transacción (TCT) integra los costos tradicionales al } \\
\text { medio ambiente y une a los costos comunes los medioambientales usando } \\
\text { los principios de contabilidad (De la Rosa, 2009:64). Tiene como objetivos } \\
\text { identificar las fuentes de los costos de transacción (aquellas características } \\
\text { o dimensiones de una transacción que hacen el intercambio problemático o } \\
\text { sumamente costoso) y especificar el mecanismo de gobierno que puede } \\
\text { coordinar de la manera más eficiente la transacción, de tal forma que se } \\
\text { logren economizar dichos costos (Jones, 1987:199 citado por Salgado, } \\
\text { 2003:63). }\end{array}$ \\
\hline Costos de transacción & $\begin{array}{l}\text { De acuerdo con Dahlman (1979 citado por Vargas, 2005), Los costos de } \\
\text { transacción son los costos de búsqueda e información, costos de } \\
\text { negociación y decisión, y los costos de formulación y aplicación de las } \\
\text { políticas. En los costos de transacción, las categorías de medición de los } \\
\text { costos ambientales (Rast y Jacqueline, } 2001 \text { citados por De la Rosa, } \\
\text { 2009:64) parten de dos criterios básicos: el primero es la consideración de } \\
\text { costos directos, como la mano de obra, la energía utilizada, las acciones } \\
\text { remediales, los servicios profesionales, etc. y el segundo los costos, } \\
\text { relacionados. En aquellos, se puede dibujar una línea directriz muy } \\
\text { marcada con las dimensiones contables de los costos sociales, los cuales } \\
\text { toman como criterio la internalización de las externalidades, producto del } \\
\text { impacto al medio ambiente (De la Rosa, 2009:64). }\end{array}$ \\
\hline
\end{tabular}


Tabla 1. Continuación...

\begin{tabular}{|c|c|}
\hline Propuesta teórica & Argumento \\
\hline $\begin{array}{l}\text { Características de los Costos } \\
\text { de } \\
\text { transacción }\end{array}$ & $\begin{array}{l}\text { Éstos costos se ven afectados por diversas situaciones como las } \\
\text { condiciones generales, los contratos y subcontratos, el riesgo, el reemplazo } \\
\text { de equipos, los sistemas de manejo de desechos, la duración de las } \\
\text { especificaciones y consideraciones por remediación completa, tiempo de } \\
\text { atención, rango de contaminación, naturaleza, volumen de la } \\
\text { contaminación, y los niveles tecnológicos necesarios (De la Rosa, } \\
\text { 2009:64). }\end{array}$ \\
\hline $\begin{array}{l}\text { Antecedentes de riesgos y } \\
\text { enfermedades en la industria } \\
\text { de la transformación de la } \\
\text { madera }\end{array}$ & $\begin{array}{l}\text { Un estudio elaborado por Pedersen, Hannerz, Tüchsen, Mikkelsen y } \\
\text { Dyreborg (2010:149) identifica ocho industrias asociadas con elevados } \\
\text { riesgos significativos de lesiones para cinco regiones dadas (Extremidades } \\
\text { inferiores, cabeza y cuello, tórax, extremidades superiores y espalda). Entre } \\
\text { éstas la de "albañil, carpintero y trabajos de carpintería”. Así mismo varios } \\
\text { estudios han mostrado desórdenes respiratorios en carpinteros, incluyendo } \\
\text { las pruebas de reducción de la función pulmonar en éstos trabajadores } \\
\text { (Borm P.J. et al., 2002, citado por Boskabady, Rezaiyan, Navabi, Shafiei y } \\
\text { Arab, 2010: 1003). Eriksson, Wiklund y Larsson (2004:274) detectaron } \\
\text { que aserrar en talleres de carpintería y la recolecta en los aserraderos de } \\
\text { pino y abeto causaron una considerable exposición dérmica a resinas } \\
\text { ácidas. No obstante, además están expuestos a varios posibles riesgos } \\
\text { respiratorios como el aserrín, formaldehido, solventes, sulfato de cobre, } \\
\text { sulfato de hierro, pentaclorofenol, fenol, pegamentos, cromatos, yeso, } \\
\text { fibras minerales, aislantes, poliuretano, adhesivos, barnices y acrilatos, y } \\
\text { éstos trabajadores tenían una elevada tasa de mortalidad equilibrada en el } \\
\text { área de enfermedades respiratorias, incluyendo cáncer (Robinson, 1996 } \\
\text { citado por Hossain et al., 2010: 1006). Entre ellos, algunos de los químicos } \\
\text { usados para conferir resistencia y durabilidad a los muebles de madera } \\
\text { podrían también ser la causa para el efecto genotóxico señalado por } \\
\text { Rekhadevi et al. (2009). Otro estudio llevado a cabo por Vaughan, et al. } \\
\text { (2000:383) apoyan la hipótesis que la exposición ocupacional al } \\
\text { formaldehido incrementa el riesgo de Carcinoma nasofaríngeo (NPC)... En } \\
\text { contraste, sus resultados no fueron consistentes con evidencias sugestivas } \\
\text { que relacionen la exposición ocupacional al aserrín con el riesgo de } \\
\text { Carcinoma nasofaríngeo. }\end{array}$ \\
\hline
\end{tabular}

Fuente: Elaboración propia. 
Aquí se presenta un breve resumen de los aspectos teóricos encontrados en la literatura y que sustentan este trabajo. Éstos preceden los esfuerzos aquí plasmados.

En sí, la contabilidad como la vida misma, es una continuidad de distintos aspectos de la vida de la organización que actúa como una condición de existencia en un mundo social y económico, a través de una rendición de cuentas (De la Rosa, 2009:28). Sin embargo, no sólo es relevante dentro de los límites de una firma en particular, si no que juega un papel más general, lo que es de interés son las conexiones cercanas que han sido demostradas entre la contabilidad y los procesos sociales como sugieren Hopwood and Miller (1994 citados por Lovell, H. y MacKenzie, D., 2011:707). Éstas pueden jugar un papel fundamental para un desempeño más sustentable de las actividades humanas, a través de una toma de decisiones más responsable y verde. Apoyándose en la contabilidad ambiental, como un monitor de las acciones llevadas a cabo por la gerencia y estrategia de control de las mismas.

También se tomará en cuenta la propuesta de Picazo (1994 citado por De la Rosa, 2009), en que reposa la responsabilidad de definir los costos contables medioambientales, a la normativa contable y propone valuar éstos mediante indicadores internos. Esto, para darle lógica, homogeneidad, concreción y validez oficial en la práctica contable, pero que además logre ser de utilidad para atender la demanda de información de esta naturaleza en las organizaciones. Tal propuesta, permitirá a las organizaciones conocer qué parte de los costos en que incurre son relativos a lo medio ambiental, en qué medida estos aumentan o disminuyen de acuerdo a las políticas adoptadas y en qué grado éstas golpean los resultados del ejercicio.

La contabilidad clásica, ciertamente tiene limitaciones al respecto que deben ser superadas si se quiere captar la realidad como tal. Está claro que la externalización de costos como los anteriores factores comentados son una realidad. Seguro deben existir varias maneras de evitar las externalidades sin incurrir en mayor costo de acuerdo a la naturaleza de las consecuencias. Sin embargo, la manera más eficiente, quizás la más barata y menos dañina de lograrlo es evitando que sucedan. Lo cual involucra la inversión en prevención y control. Éste enfoque se considera en el presente trabajo. No obstante, para lograr que las organizaciones se convenzan de internalizar esos costos hay que persuadirlos de los beneficios que contrae para todas las partes involucradas.

Se tomará como punto de partida la teoría de la multicausalidad, enfocada a la salud del trabajador. Siguiendo la idea de que la salud y la enfermedad de las personas es el resultado de muchos factores que inciden significativamente en el proceso que se da entre la vida y la muerte de cada individuo (Osorio, 2012). En el caso que nos ocupa, son todos aquellos factores que acompañan el proceso de producción en el área de trabajo. Por eso, la importancia del estudio de caso llevado a cabo en el presente trabajo; para identificar los riesgos inherentes a dicho proceso y que habrán de prevenirse para minimizar los riesgos a todas las partes involucradas en la relación laboral.

\section{Objeto de estudio: las carpinterías}

El estudio de caso, se llevó a cabo mediante una metodología cualitativa, usando como herramientas la observación directa, imágenes de los establecimientos objeto del estudio, entrevistas a los trabajadores, búsqueda bibliográfica $\mathrm{y}$ en bases de datos, el razonamiento deductivo y la extrapolación.

El objetivo, fue detectar las consecuencias derivadas de una mala gestión medioambiental y de esta manera aportar información con el fin de apoyar las decisiones de la directiva, sugiriendo una inclinación más responsable social y ambientalmente. El resultado de corregir las acciones irresponsables relacionadas con la 
salud, seguridad y medioambiente, sería la generación egresos por concepto de equipo de protección personal y dispositivos de control ambiental. Lo cual se vería reflejado en el concepto de costos adecuado, y en consecuencia, en el estado resultados, y ya no como egresos disimulados.

La carpintería, como todas las actividades productivas de la rama de la transformación, tiene como objetivo la utilización de las materias primas y materiales indirectos para producir un producto final. Éste es tan variado como la necesidad del cliente, ya que la madera se ha adecuado a casi cualquier aspecto de la vida del hombre. Por ser uno de los primeros materiales utilizados, se pueden producir desde muebles hasta complementos de inmobiliario como cajones, closets, marcos de ventana y además otros productos con valor residual. A veces el oficio del carpintero, también se extiende más allá del taller, llevándolo a actividades como el transporte y la instalación de artefactos de madera en el hogar, talleres u otros lugares.

Dentro de una carpintería se utilizan distintas herramientas y máquinas para diferentes actividades que están relacionadas con la manipulación de la madera. La mayoría de ellas tienden a la reducción de la materia prima para darle la forma que conviene, por lo que gran cantidad de ellas son de bordes afilados o navajas. Existen varias herramientas de diferente naturaleza para trabajar la madera en estos talleres, quizás algunas dignas de mención, son aquellas que tienen como fin darle cubierta y acabado a la madera, como los compresores, brochas para pinturas y recubrimientos. Los residuos de las carpinterías por lo general son trazas de madera también llamado virutas o aserrín, que son sólidos de diferentes tamaños. Pero además, debido a los materiales indirectos utilizados, también se generan otro tipo de residuos como los metálicos (que son menos frecuentes) y emisiones como los aerosoles de productos volátiles orgánicos que son potencialmente nocivos para la salud y el medioambiente.

Una de dichas externalidades que más apura, es la de enfermedades de trabajo, hay que recordar que la productividad depende en cierto grado y situación de los trabajadores. Es obvio que un trabajador no puede ser productivo si no se encuentra en un estado óptimo de salud. De hecho, otra posible consecuencia, puede ser la frecuente renuncia de personas insatisfechas con el entorno laboral. Esto se reflejaría en una alta rotación de empleados, lo cual conlleva costos inherentes al reclutamiento, además de otras consecuencias con repercusión financiera. Así mismo hay que señalar la posibilidad de que si la fuente contaminante se encuentra fuera de control, incluso puede llegar a afectar a las comunidades aledañas.

La carpintería, es una práctica muy antigua y ha variado sus técnicas y características; transformando sus prácticas con el tiempo, con el objetivo satisfacer las necesidades humanas específicas en regiones diferentes. De esta manera encontramos que éste oficio es mucho más amplio y requerido en ciertas regiones, en donde las viviendas se construyen típicamente con materiales derivados de la madera. La carpintería utiliza herramientas pesadas, a veces eléctricas y diversos materiales directos e indirectos que se han ido adecuando a conveniencia de la calidad del producto, sin embargo, esto ha traído riesgos al trabajador. Un estudio elaborado por Pedersen, Hannerz, Tüchsen, Mikkelsen y Dyreborg (2010:149), identifica ocho actividades asociadas con elevados riesgos significativos de lesiones en cinco zonas corporales: extremidades inferiores, cabeza y cuello, tórax, extremidades superiores y espalda. Entre ellas están las de: albañil, carpintero y trabajos de carpintería. 
En medicina del trabajo, la asociación de una causa potencialmente dañina a la salud con una alteración patológica se sospecha cuando se identifica un aumento de los factores causales y hay un incremento en la ocurrencia de los casos patológicos (Instituto Mexicano del Seguro Social, 1983:37). Así mismo, varios estudios han mostrado desórdenes respiratorios en carpinteros, incluyendo pruebas de reducción de la función pulmonar en éstos trabajadores (Borm et al., 2002, citado por Hossain et al., 2010: 1003). Investigaciones de carpinteros en una región de Irán mostraron una reducción en la Prueba de Función Pulmonar (PFT) en estos, lo cual puede indicar una enfermedad pulmonar obstructiva en estos trabajadores (Hossain et al., 2010: 1006). Además, la carpintería se asoció con una alta frecuencia de síntomas respiratorios relacionados con el trabajo, y en menor grado, con síntomas alérgicos. Éstos, son particularmente agravados después de exposición a irritantes en el lugar de trabajo principalmente al aserrín (Hossain et al., 2010: 1006) presente en estos centros de trabajo.

El objetivo de este trabajo fue revisar el impacto ambiental en la salud laboral y su posible acercamiento a indicadores de costos socio ambientales laborales, que arrojen datos útiles para las organizaciones y que se relacionen con la repercusión del medioambiente interno laboral. El motivo de ésta investigación, es que frecuentemente no está claro qué acciones de una organización y sus consecuencias en el ambiente le afectan a sí misma de manera directa. Esto se debe a que se adolece de un método, herramientas y normatividad para traducir el daño financiero en lenguaje contable. Por tanto, se justifican los esfuerzos en esta área, con el fin de plantear la orientación de las decisiones de la directiva hacia una situación ganar-ganar en la que los empleados puedan gozar de mejor salud y calidad de vida, a la vez que las empresas puedan mantener una buena productividad. Situándoles en un escenario optimista que permita la reducción de costos, además de la posibilidad de contribuir al desarrollo de una sociedad más sustentable.

Para iniciar el aserrín, es un producto de desecho de la transformación de la madera y sus partículas suspendidas en el aire, se han señalado ampliamente en la literatura como un problema potencial de salud (Hossain et al., 2010; Eriksson, Wiklund y Larsson, 2004; Rekhadevi et al., 2009). Eriksson, Wiklund y Larsson (2004:274) detectaron que aserrar en talleres de carpintería y la recolecta en los aserraderos de pino y abeto causaron una considerable exposición dérmica a resinas ácidas. Las manos parecieron tener la mayor exposición... pero además, la identificación de resinas ácidas en el pecho interno y en la parte frontal interna baja de la pierna derecha indica que es probable que las sustancias penetren o que se filtren a través de la ropa y contaminen la piel del trabajador (Eriksson, Wiklund y Larsson, 2004:274).

No obstante, además están expuestos a varios posibles riesgos respiratorios como el aserrín, formaldehido, solventes, sulfato de cobre, sulfato de hierro, pentaclorofenol, fenol, pegamentos, cromatos, yeso, fibras minerales, aislantes, poliuretano, adhesivos, barnices y acrilatos, y éstos trabajadores tenían una elevada tasa de mortalidad equilibrada en el área de enfermedades respiratorias, incluyendo cáncer (Robinson, 1996 citado por Hossain et al., 2010: 1006). Entre ellos, algunos de los químicos usados para conferir resistencia y durabilidad a los muebles de madera podrían también ser la causa para el efecto genotóxico señalado por Rekhadevi et al. (2009), aunque se señala principalmente al aserrín. Dicho efecto puede resultar en cáncer. Por otra parte, otro estudio llevado a cabo por Vaughan, et al. (2000:383) apoya la 
hipótesis que la exposición ocupacional al formaldehido incrementa el riesgo de Carcinoma nasofaríngeo (NPC, por sus siglas en inglés)... En contraste, sus resultados no fueron consistentes con evidencias sugestivas que relacionen la exposición ocupacional al aserrín con el riesgo de carcinoma nasofaríngeo.

Muchos de los distintos materiales de trabajo utilizados en la industria de la transformación de la madera, son señalados como sospechosos de causar afecciones respiratorias y otros síntomas. Algunos otros han sido catalogados como cancerígenos, como es el caso del formaldehido (INSHT, 2010) y algunos otros componentes de pinturas, barnices y lacas. El aserrín y el polvo derivado de la actividad de aserrar se señalan en la bibliografía como sospechosos de causar estados patológicos respiratorios y cancerígenos. En conjunto, los riesgos que acompañan la actividad rutinaria de aquellos que laboran en los centros de trabajo inseguros (como los aquí estudiados), pueden llegar a ocasionar malestares y patologías que conllevan a consecuencias negativas a las empresas, tal como señala la OMS (2010:6), sustentando lo establecido.

\section{Resultados}

En vista de la amplia gama de riesgos y exposiciones laborales que se presentan tanto para el oficio de la carpintería, como para empresas relacionadas con la fabricación de muebles y otros derivados de la madera. Se hacen presentes los posibles daños a la salud que aquellos pueden causar a los empleados, y consecuentemente, a las empresas en su estado financiero. Esto, justifica el análisis y la consideración de costos derivados de la contaminación ambiental interna, producto de las actividades de las empresas de este rubro y la desregulación que las caracteriza. Dichas acciones pueden expresarse como malestar e inestabilidad en los trabajadores, como se comentó previamente. Por tanto, podrían ser captadas como repercusiones negativas en los estados financieros; a través de indicadores del costo enfocados, en este caso particular, a captar las consecuencias de las acciones negligentes con el medio ambiente. Esto representa la oportunidad de relacionar el beneficio al capital y una mayor productividad, con el control de emisiones y la salvaguarda de la calidad del aire. Que por consecuencia traería una disminución del impacto a la salud, un ambiente más saludable y mayor calidad de vida a la planta de empleados.

A partir del estudio aplicado a tres carpinterías de la ciudad de Guaymas, Sonora, se encontró lo siguiente:

En general el proceso puede iniciar desde la customización (es decir, el (1) trato con el cliente) o bien, con la (2) compra de los materiales en rústico (madera rústica), y proceder esta con aquella etapa o viceversa. Esto se debe a que el cliente a veces tiene necesidades o preferencias ya establecidas, o bien, a veces está abierto a sugerencias y otras opciones.

El (1) trato con el cliente, es una breve conversación personal entre el carpintero y el cliente, quien busca construir, reparar o comprar un mueble. Primeramente se discute el tipo de mueble, las medidas (largo, ancho y grosor), el tipo de madera, se hace un bosquejo rápido, se elige la pintura, el acabado y el finalmente el precio.

La (2) compra de material en rústico se hace al proveedor bajo situación normal, según lo que falta en inventarios o bien, bajo pedido del cliente.

Una vez sabido lo que se hará, se hacen (3) cálculos de las dimensiones deseadas para el mueble y se pasan al (4) marcado sobre la madera.

Posteriormente se hace el (5) cortado de la madera con sierra eléctrica para obtener las piezas del mueble o 
bien, el trozo de madera en donde se dará forma al mueble.

Después, se pasa a la canteadora (o cateadora), una máquina que sirve para (6) enderezado de la madera. La canteadora puede incluir o no navaja, con fines de quitarle lo rústico a la madera, auxiliando en la (7) eliminación de las asperezas.

Hecho lo anterior, se utiliza el cepillo de grueso para terminar la (7) eliminación de las asperezas, éste paso puede ser a veces omitido o no.

Así listo el mueble, se pasa al (8) trazado de medidas y dimensiones internas del mueble(es decir, si tiene cajones, bisagras, eminencias, depresiones, relieves, etc. en caso de ser necesario, ya que no todos los tipos de muebles lo requieren)

Posterior a la etapa anterior, se pasa al uso del escoplo, en donde se llevan a cabo los detalles y entre ellos la (9) creación de un hueco (llamado hembra), mientras que otras piezas se pasan a la espigadora para la (9) creación del macho (una eminencia) ambos en los vértices de las piezas que unirán al mueble.
El (10) armado del mueble es la siguiente etapa, en donde puede o no usarse pegamento de diferentes tipos. Hecho esto, se pasa a hacerse el (11) lijado del mueble, con lija o lijadora. Si terminado éste,(12) el mueble tiene daños (golpes o rasguños), ha de pasarse al(13) resanado de los daños (en donde se utiliza resanador para llevarse a cabo) seguido por otro(14) lijado en dichas zonas resanadas previo al (15) pintado del mueble. De lo contrario, se pasa directamente al (15) pintado del mueble, en esta etapa se agrega la pintura por medio de una pistola pulverizadora.

Ya pintadas las superficies, se procede al (16) aplicado de sellador y ya para finalizar el mueble, a la aplicación del (17) acabado brillante, laca o barniz sobre la obra. La (18) entrega al cliente se vuelve potencialmente parte del proceso de fabricación, ya que a veces lo hecho requiere una instalación o entregarse a domicilio, pero en otras ocasiones es recogido en el establecimiento.

Considerando la numeración del proceso, en la figura 1 se presenta el proceso general de fabricación de muebles descrito anteriormente. 
Figura 1. Proceso general de fabricación de muebles

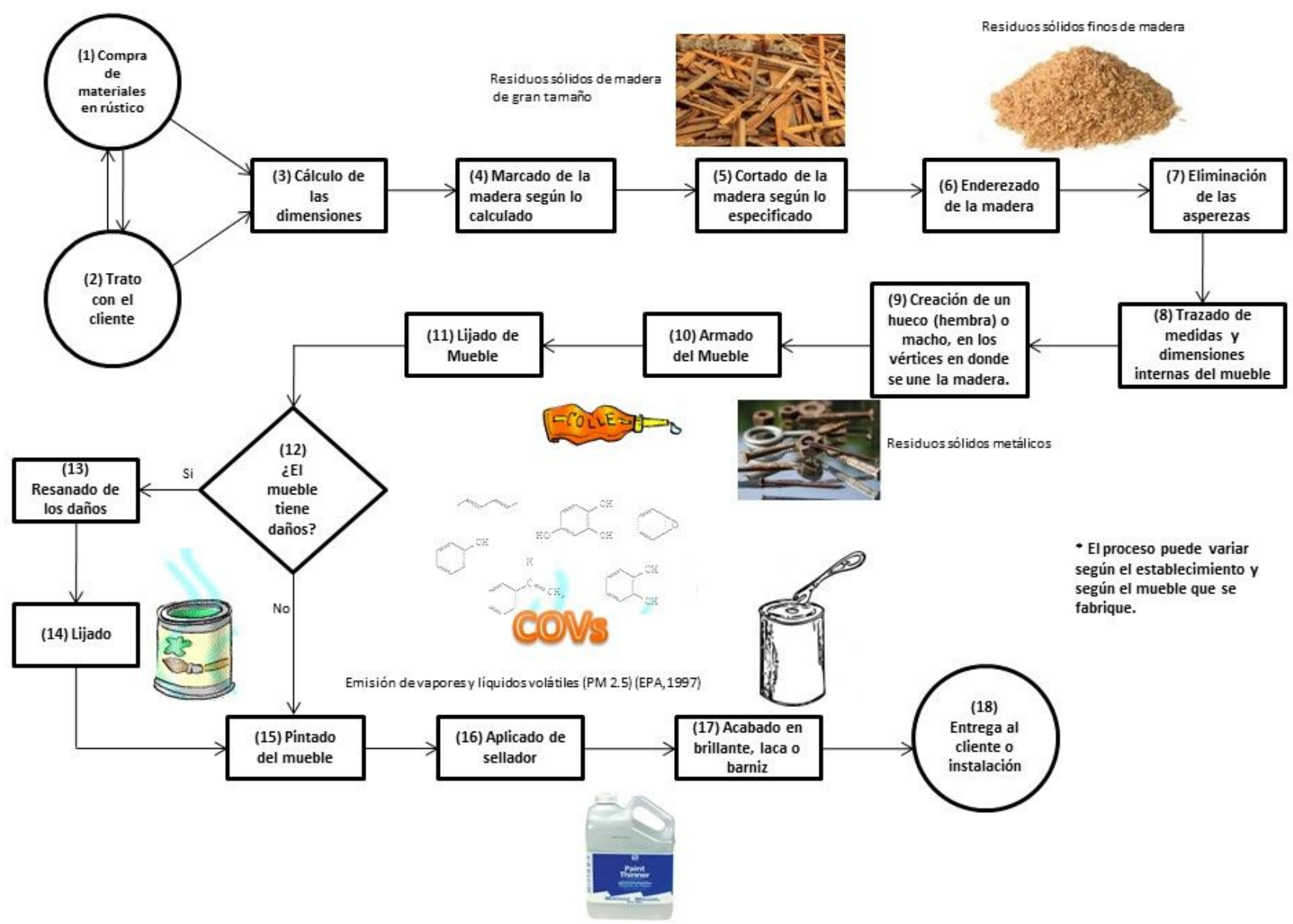

Fuente: Elaboración propia, análisis de resultados.

Son varios momentos, en los cuales existe una causa de daño a la salud, en la figura 2 se presentan las actividades que provocan daño a la salud laboral de los empleados de las carpinterías. 
Figura 2. Actividades del proceso de producción de muebles relacionados con los daños a la salud y consecuencias

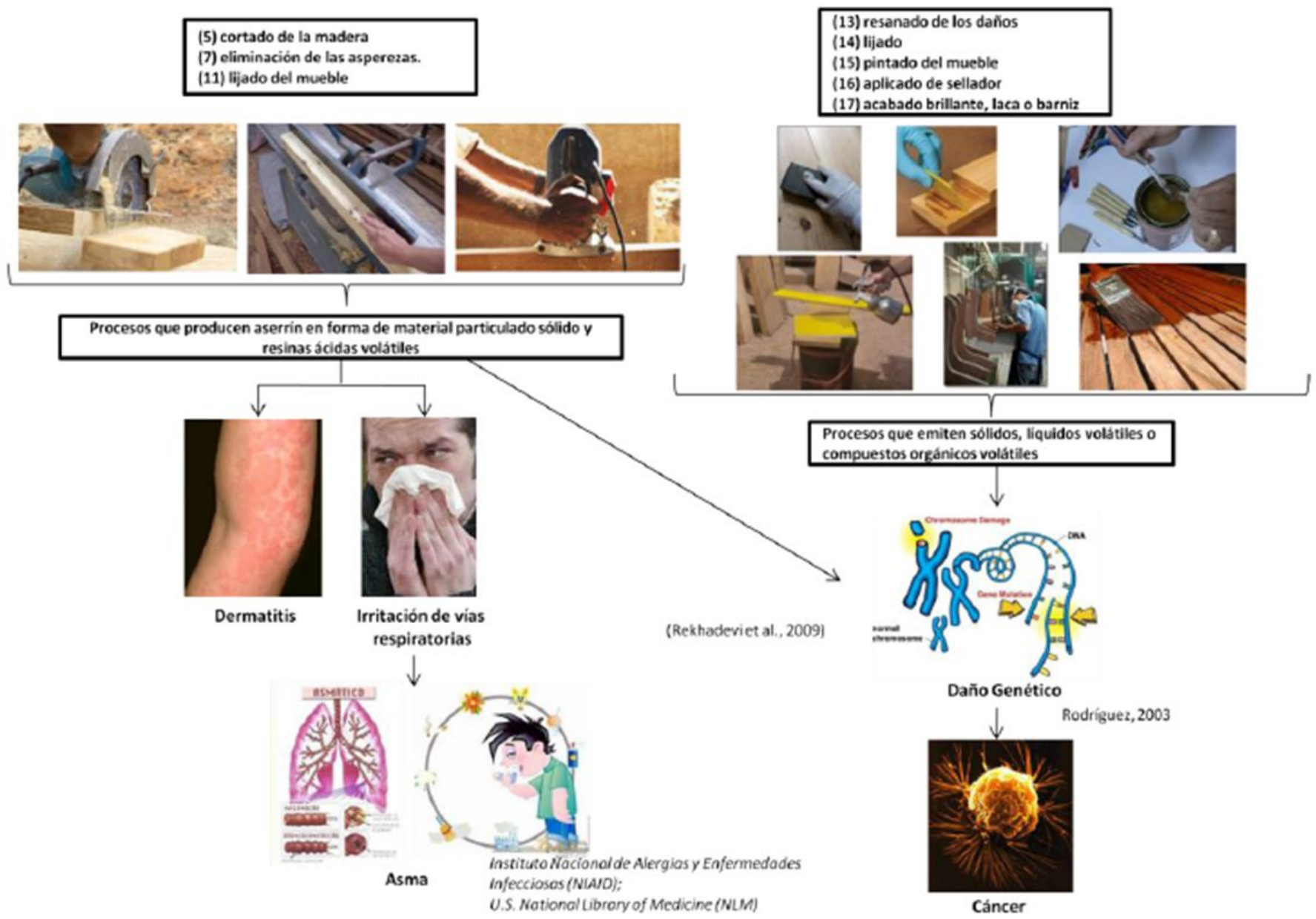

Fuente: Elaboración propia, análisis de resultados.

Muchos de los distintos materiales de trabajo utilizados en la industria de la transformación de la madera, son señalados como sospechosos de causar afecciones respiratorias y otros síntomas. Algunos otros han sido catalogados como cancerígenos, como es el caso del formaldehido (INSHT, 2010) y algunos otros componentes de pinturas, barnices y lacas. El aserrín y el polvo derivado de la actividad de aserrar se señalan en la bibliografía como sospechoso de causar estados patológicos respiratorios y cancerígenos. En conjunto, los riesgos que acompañan la actividad rutinaria de aquellos que laboran en los centros de trabajo inseguros (como los de este trabajo), pueden llegar a ocasionar malestares y patologías que conllevan a consecuencias negativas a las empresas, tal como señala la OMS (2010:6), sustentando en éste trabajo.

\section{Conclusiones}

Este trabajo se basó en la teoría de costos de transacción mezclada con el criterio de costos sociales 
por las consideraciones antes expuestas. Ya que es apropiado reconocer costos ambientales como aquellos derivados de la salud del trabajador, en los costos de transacción subsecuentes del contrato de trabajo. Usualmente, las consecuencias de no hacerlo generan un costo integrado en los egresos que no se identifica o se oculta. Este costo de transacción afecta el resultado del período y la acción que conlleva externalizar las consecuencias al trabajador. Invertir en la prevención de riesgo laboral, reduce ambas cosas, y a la vez, sustituye un costo no aparente en el estado de resultados que no se refleja en el precio de venta, por un costo de producción indirecto perfectamente medible y probablemente más económico. Esto resultaría en una manera más eficiente de hacer las cosas en las organizaciones, y a su vez, de identificar costos ambientales dentro de los costos tradicionales.

\section{Referencias}

Aranguren Gómez, N., y Ochoa Laburu, E. (2008). Divulgación de información sobre empleados y medioambiente en España y Alemania: una nota de investigación. RC-SAR 11(2) pp. 123-142.

Azqueta, D., y De la Cámara, G. (2008). El costo ecológico de la extracción del petróleo: una simulación. Revista de la CEPAL (94). pp. 59-74.

Boskabady, M., Rezaiyan, M., Navabi, I., Shafiei, S., Arab, S. (2010). Work-related respiratory symptoms and pulmonary function tests in northeast Iranian (the city of Mashhad) carpenters. Clinics, 65(10), pp. 10031007. https://doi.org/10.1590/S1807-

\section{3}

Correa, C., y Moneva, J. M. (2011). Special issue on social responsibility accounting and reporting in times of 'sustainability downturn/crisis. Revista de Contabilidad-Spanish Accounting Review, 14, Pp. 187211.
Cortés-Landázury, R. (2011). ¿La tragedia de los comunes o lo común de las tragedias?: La dialéctica socioambiental de las basuras en el norte del Cauca. Biotecnología en el Sector Agropecuario $y$ Agroindustrial, 9(2), pp.188-197

De la Rosa, M. E. (2010). De la educación a la gestión organizacional. En Carmona, E.A., (Ed.) De la educación a la gestión organizacional. Aguascalientes, México: Instituto Tecnológico de Aguascalientes.

De la Rosa, M. E. (2009). El medio ambiente y las organizaciones. En De la Rosa, M.E. et al. (Ed.) Gestión y fiscalización en las organizaciones. Hermosillo, México: Editorial Universidad de Sonora

De la Rosa Leal, M. E. (2009). Modelo de costos medioambientales contables: metodología y caso industria maquiladora. México, D.F.: Plaza y Valdés Editorial

Del Río-González, C. (2003). Costos para administradores y dirigentes. México, D.F.: CENGAGE Learning.

Déniz Mayor, J. J. (2006). Contabilidad nacional, full cost accounting y resultado contable empresarial ambientalmente sostenible. Cuadernos de Administración. Bogotá (Colombia), 19(32) pp. 157178.

Eriksson, K., Wiklund, L., y Larsson, C. (2004). Dermal exposure to terpenic resin acids in Swedish carpentry workshops and sawmills. The Annals of occupational Hygiene, 48(3), pp. 267-275. https://doi.org/10.1093/annhyg/meh013

Hardin, G. (1968). The tragedy of the commons. Science Magazine, 162, pp. 1243-1248. 
INSHT. (2010). Instituto Nacional de Seguridad e Higiene en el Trabajo. NTP 873: Prevención de la exposición a formaldehido.

http://www.insht.es/InshtWeb/Contenidos/Documentac ion/FichasTecnicas/NTP/Ficheros/821a921/873w.pdf

Instituto Mexicano de Contadores Públicos. (2019). Normas de Información Financiera. México: Instituto Mexicano de Contadores Públicos.

Instituto Mexicano del Seguro Social. (1983). Lecturas en materia de seguridad social. Enfermedades de trabajo. México, D.F. Editorial de la Jefatura de publicaciones del instituto mexicano del seguro social. Pp. 37

Keller Dos Santos, M. (2005). Beneficios ambientales derivados de lean production. Memoria de Trabajos de Difusión Científica y Técnica, Universidad de Montevideo. (4), pp. 75-90.

Label, W.A. (2000). ISO 14000: un sistema de administración ambiental con oportunidades para contadores y otros consultores. Revista Contaduría y Administración, (198), pp. 55-66

Lovell, H. y MacKenzie, D. (2011). Accounting for carbon: The role of accounting professional organizations in governing climate change. Antipode, 43(3), pp. 704-730. https://doi.org/10.1111/j.14678330.2011.00883.x

Manahan, S. (2010). Environmental Chemistry. USA: CRC Press National Paint and Coating Association (2001). HMIS ${ }^{\circledR}$ Implementation Manual, Third Edition.
OMS. (2010). Informe sobre la salud en el mundo 2010. Organización mundial de la Salud. https://www.who.int/whr/2010/es/

Osorio García, S. N. (2012). El pensamiento complejo y la transdisciplinariedad: fenómenos emergentes de una nueva racionalidad. Revista de la Facultad de Ciencias Económicas, (XX) junio, pp.269-291.

Pedersen, B., Hannerz, H., Tüchsen, F., Mikkelsen, K., y Dyreborg, J. (2010). Industry and injury related hospital contacts: a follow-up study of injuries among working men in Denmark. Journal of Occupational Health, 52, pp. 147-152.

Pontelli, D., Ingaramo, R., Zanazzi, J. L., Chayle, A., Rodríguez, J., y Beale, C. (2010). Análisis de las condiciones de riesgos laborales. Propuesta para identificar los factores que la afectan, basada en el modelo de las desviaciones. Ingeniería Industrial, 9(2), pp. 7-26.

Rekhadevi, P. V. (2009). Genetic damage in wood dustexposed workers. Mutagenesis, 24(1), pp. 59-65. https://doi.org/10.1093/mutage/gen053

Romero-López, A. J. (2010). Principios de contabilidad. México, D.F.: McGraw-Hill.

Salgado C.E. (2003). Teoría de costos de transacción: una breve reseña. Cuadernos de Administración, (16) núm. 26, pp. 61-78

Secretaría del Trabajo y Previsión Social. (2008). NOM017-STPS-2008. Equipo de protección persona. Selección, uso y manejo en los centros de trabajo. http://www.stps.gob.mx/bp/secciones/dgsst/normativid ad/resumen.html\#N017 
Silva Arroyave, S. M. y Correa Restrepo, F. (2010). Los instrumentos económicos como incentivos a la internalización de costos ambientales en empresas floricultoras. Pensamiento \& gestión, (29) pp.25-55.

Vargas-Hernández, J. G. (2005). Análisis de Fundamentos de la teoría institucional. Revista digital universitaria, 6(8).
Vaughan, T. L. (2000). Occupational exposure to formaldehyde and wood dust and nasopharyngeal carcinoma. Occupational \& Environmental Medicine, 57, pp. 376-384

Wilcox, D. L., Cameron, G. T., y Xifra, J. (2006). Relaciones públicas: estrategias y tácticas. Boston, EUA: Pearson Education. 